\title{
Carbon formation on nickel and nickel-copper alloy catalysts
}

\author{
Kohlenstoffbildung auf Nickel und Nickel-Kupfer-Legierungskatalysatoren \\ I. Alstrup*, M. T. Tavares, C. A. Bernardo, \\ O. Sørensen, and J. R. Rostrup-Nielsen
}

\begin{abstract}
Equilibrium, kinetic and morphological studies of carbon formation in $\mathrm{CH}_{4}+\mathrm{H}_{2}, \mathrm{CO}$, and $\mathrm{CO}+\mathrm{H}_{2}$ gases on silica supported nickel and nickel-copper catalysts are reviewed. The equilibrium deviates in all cases from graphite equilibrium and more so in $\mathrm{CO}+\mathrm{CO}_{2}$ than in $\mathrm{CH}_{4}+\mathrm{H}_{2}$. A kinetic model based on information from surface science results with chemisorption of $\mathrm{CH}_{4}$ and possibly also the first dehydrogenation step as rate controlling describes carbon formation on nickel catalyst in $\mathrm{CH}_{4}+\mathrm{H}_{2}$ well. The kinetics of carbon formation in $\mathrm{CO}$ and $\mathrm{CO}+\mathrm{H}_{2}$ gases are in agreement with $\mathrm{CO}$ disproportionation as rate determining step. The presence of hydrogen influences strongly the chemisorption of CO. Carbon filaments are formed when hydrogen is present in the gas while encapsulating carbon dominates in pure CO. Small amounts of $\mathrm{Cu}$ alloying promotes while larger amounts $(\mathrm{Cu}: \mathrm{Ni} \geq 0.1)$ inhibits carbon formation and changes the morphology of the filaments ("octopus" carbon formation). Adsorption induced nickel segregation changes the kinetics of the alloy catalysts at high carbon activities. Modifications suggested in some very recent papers on the basis of new results are also briefly discussed.
\end{abstract}

Es wird eine Übersicht gegeben über Gleichgewicht, kinetische und morphologische Untersuchungen der Kohlenstoffabscheidung in $\mathrm{CH}_{4}+\mathrm{H}_{2}, \mathrm{CO}$ und $\mathrm{CO}+\mathrm{H}_{2}$ Gasgemischen. In allen Fällen weicht das Gleichgewicht ab von dem Gleichgewicht mit Graphit, und zwar mehr in den $\mathrm{CO}+\mathrm{CO}_{2}$ als in den $\mathrm{CH}_{4}+\mathrm{H}_{2}$ Gemischen. Ein kinetisches Modell, das aus Informationen aus der Oberflächenforschung abgeleitet wurde, führt zur Chemisorption von $\mathrm{CH}_{4}$ und wahrscheinlich auch dem ersten Dehydrierungsschritt als geschwindigkeitsbestimmenden Schritten und beschreibt die Kohlenstoffabscheidung auf Nickelkatalysatoren auf $\mathrm{CH}_{4}+\mathrm{H}_{2}$ gut. Die Kinetik der Kohlenstoffbildung in und $\mathrm{CO}+\mathrm{H}_{2}$ Gasgemischen ist in Übereinstimmung mit der Annahme der CO-Disproportionierung als geschwindigkeitsbestimmenden Schritt. Die Anwesenheit von Wasserstoff beeinflußt die Chemisorption von $\mathrm{CO}$ sehr stark. Kohlenstoffäden werden gebildet, wenn Wasserstoff in dem Gas anwesend ist, während in reinem CO die Einkapselung durch Kohlenstoff vorwiegt. Kleine Gehalte von $\mathrm{Cu}$ beschleunigen die Kohlenstoffbildung, während größere Gehalte $(\mathrm{Cu}: \mathrm{Ni} \geq 0,1)$ die Kohlenstoffabscheidung hemmen und die Morphologie der Fadenbildung ändern ("Octopus" Kohlenstoffabscheidung). Durch Adsorption induzierte Nickelsegregation verändert die Kinetik für die Legierungskatalysatoren bei hohen Kohlenstoffaktivitäten. Veränderungen der kinetischen Modelle, die in einigen vor kurzem erschienenen Veröffentlichungen vorgeschlagen wurden auf der Grundlage von neuen Resultaten, werden auch kurz diskutiert.

\section{Introduction}

The first step in transforming natural gas, consisting mainly of methane, into useful chemicals in the chemical industry is usually the steam reforming reaction where methane is reacted with steam to a mixture of hydrogen, carbon monoxide and carbon dioxide by means of a nickel catalyst. Thus, the hydrogen used for ammonia synthesis and the syngas, i. e. a mixture of hydrogen and carbon monoxide, used for methanol syn-

\footnotetext{
* I. Alstrup, O. Sфrensen, J. R. Rostrup-Nielsen Haldor Topsøe Research Laboratories Nymøllevej 55, DK-2800 Lyngby (Denmark)

M. T. Tavares, C. A. Bernardo

School of Engineering, Universidade do Minho P-4800 Guimarães (Portugal)
}

thesis is usually produced by steam reforming of natural gas. The reaction design conditions are limited by the requirement that filamentous carbon formation must be avoided because it can destroy the catalyst particles and block the reactor. The importance of being able to predict accurately the conditions at which the formation of filamentous carbon may take place has been a strong motivation for a large number of studies of carbon formation on nickel catalysts for more than 25 years. The first model explaining the growth of filamentous carbon on silica and graphite supported nickel films exposed to $\mathrm{C}_{2} \mathrm{H}_{2}$ was suggested by Baker et al. [1] on the basis of observations in controlled atmosphere electron microscope. They suggested that carbon atoms from the decomposition of $\mathrm{C}_{2} \mathrm{H}_{2}$ on the nickel surface diffuse through the nickel particle and segregate initially to the interface between particle and support causing detachment of the particle. In the subsequent steady state carbon filament growth period, the decomposition, bulk diffusion and segregation continue but now the segregated carbon contributes to the filament growth. A simi- 
lar mechanism was suggested independently by Lobo et al. [2]. Baker et al. [1] postulated that the diffusion through the particle was rate determining and that the driving force was a temperature gradient caused by the heat liberated by the decomposition of $\mathrm{C}_{2} \mathrm{H}_{2}$. In a subsequent paper, Baker et al. [3] provided supporting evidence for bulk diffusion as rate determining by measurements of the activation energies for carbon filament growth on $\mathrm{Fe}, \mathrm{Co}, \mathrm{Cr}$ and $\mathrm{Ni}$ exposed to $\mathrm{C}_{2} \mathrm{H}_{2}$, which were found to be equal to the activation energies for carbon diffusion through the bulk of the metals.

In the present paper the mechanism of carbon formation is discussed mainly on the basis of the results obtained in our studies of carbon formation on silica supported nickel and nickel-copper alloy catalysts. Kinetic and equilibrium results as well as electron microscopic observations are reviewed. On this basis, supplemented with results from the literature, our present understanding and lack of understanding of the various steps of carbon formation in the steam reforming process on nickel and nickel-copper catalysts are discussed.

\section{Kinetic studies}

Simultaneous with the methane steam reforming reaction

$\mathrm{CH}_{4}+\mathrm{H}_{2} \mathrm{O} \rightleftarrows \mathrm{CO}+3 \mathrm{H}_{2}$

also the water gas shift reaction

$\mathrm{CO}+\mathrm{H}_{2} \mathrm{O} \rightleftarrows \mathrm{CO}_{2}+\mathrm{H}_{2}$

takes place.

Dependent on the conditions, carbon may be formed by one or more of the following reactions

$$
\begin{aligned}
& \mathrm{CH}_{4} \rightleftarrows \mathrm{C}+2 \mathrm{H}_{2} \\
& 2 \mathrm{CO} \rightleftarrows \mathrm{C}+\mathrm{CO}_{2} \\
& \mathrm{CO}+\mathrm{H}_{2} \rightleftarrows \mathrm{C}+\mathrm{H}_{2} \mathrm{O}
\end{aligned}
$$

\subsection{Kinetics of carbon formation on $\mathrm{Ni} / \mathrm{SiO}_{2}$ catalysts from $\mathrm{CH}_{4}+\mathrm{H}_{2}$ gas mixtures}

Kinetic results were obtained at 723,773 , and $823 \mathrm{~K}$ at atmospheric pressure and with partial pressures of $\mathrm{CH}_{4}$ and $\mathrm{H}_{2}$ in the ranges $20-80 \mathrm{kPa}$ and $5-15 \mathrm{kPa}$, respectively [4]. The results were interpreted by means of a kinetic model [4] constructed on the basis of results obtained by theoretical and experimental surface science studies of the interaction of $\mathrm{CH}_{4}$ with Ni surfaces. Molecular beam [5, 6] and environmental gas [7-10] studies of the dissociative chemisorption of $\mathrm{CH}_{4}$ on $\mathrm{Ni}(111), \mathrm{Ni}(100)$, and $\mathrm{Ni}(110)$ surfaces have shown that it is a direct process resulting in the deposition of $\mathrm{CH}_{3}$ and $\mathrm{H}$ on the surface. At sufficiently high temperatures, $\mathrm{CH}_{3}$ is subsequently stepwise dehydrogenated. The chemisorption probability is strongly dependent on the crystallographic orientation of the surface, being smallest for the close packed (111) surface. At temperatures above about $625 \mathrm{~K}$, the surface $\mathrm{C}$ atoms migrate at a measurable rate into the bulk of the nickel crystal [11]. Nucleation and segregation of carbon may take place when the solubility limit has been exceeded locally [12]. Accordingly, a kinetic model for the steady rate growth of carbon filaments from $\mathrm{CH}_{4}+\mathrm{H}_{2}$ gas mixtures may be based on the following steps:

$\mathrm{H}_{2}+2 * \rightleftarrows 2 \mathrm{H}^{*}$

$\mathrm{CH}_{4}+2 * \rightleftarrows \mathrm{CH}_{3} *+\mathrm{H}^{*}$

$\mathrm{CH}_{3} *+* \rightleftarrows \mathrm{CH}_{2} *+\mathrm{H}^{*}$

$\mathrm{CH}_{2}{ }^{*}+{ }^{*} \rightleftarrows \mathrm{CH}^{*}+\mathrm{H}^{*}$

$\mathrm{CH}^{*}+* \rightleftarrows \mathrm{C}^{*}+\mathrm{H}^{*}$

where *signifies an adsorption site on the nickel surface.

To these surface reaction steps should be added steps providing transport of the carbon atoms from the surface and into the filament, i. e. corresponding to subsurface migration, diffusion through the nickel particle and segregation to the interface between the nickel particle and the carbon filament. Grabke [13] found that a kinetic model based on almost the same surface steps but with the addition of a molecularly adsorbed $\mathrm{CH}_{4}$ precursor could account for the kinetics of carbon formation on iron films from $\mathrm{CH}_{4}+\mathrm{H}_{2}$ gas mixtures, when the first dehydrogenation step was assumed to be rate determining. In the present case, all models generated by assuming that one of the steps (6)-(10) is rate determining were tested against our experimental results. The number of unknown parameters was drastically reduced by calculating the equilibrium constants of the steps using known values of the vibrational frequencies and bonding energies of the species participating in the steps. At a given temperature, the only adjustable parameters are then the forward rate constant of the rate determining step (rds), $\mathrm{k}_{\mathrm{r}}$, and the carbon coverage. It was argued [4] that the carbon coverage would stay close to the lower limit (ca. 0.2 monolayer) on the $\mathrm{Ni}(100)$ surface, and that it could be treated as a constant. With the chemisorption step (7) or the first dehydrogenation step (8) as the rds a value for the forward rate constant $\mathrm{k}_{\mathrm{r}}$, could, for any choice of the carbon coverage, be found which gave reasonable agreement between model and experiment. Other choices of rds could be excluded. Even better agreement was obtained by assuming that both steps (7) and (8) are rate controlling, i.e. cannot be treated as being close to equilibrium. After having obtained good agreement at one temperature by adjusting the two rate constants, it was possible to obtain reasonable agreement at the other temperatures by adjusting only the rate constant for the first dehydrogenation step because the temperature dependence of the chemisorption rate is known from surface science experiments $[7,8$, 10].

\subsection{Kinetics of carbon formation on $\mathrm{Ni} / \mathrm{SiO}_{12}$ catalysts from $\mathrm{CO}$}

Tøttrup [14] found that his kinetic results for carbon formation on a $\mathrm{Ni} / \mathrm{SiO}_{2}$ catalyst in $\mathrm{CO}$ and in $\mathrm{CO}+\mathrm{CO}_{2}$ gas mixtures were well described by a model in which the dissociation of $\mathrm{CO}$

$\mathrm{CO}^{*}+* \rightarrow \mathrm{C}^{*}+\mathrm{O}^{*}$

is the rds. Sakai et al. [15] concluded, on the other hand, that a kinetic model based on disproportionation of $\mathrm{CO}$ 
$\mathrm{CO}^{*}+\mathrm{CO}^{*} \rightleftarrows \mathrm{C}^{*}+\mathrm{CO}_{2} *$

as the rds gave the best agreement with their experimental results.

Tavares et al. found [16], in agreement with Sakai et al. [15], that kinetic results for carbon formation on a $\mathrm{Ni} / \mathrm{SiO}_{2}$ catalyst in CO could not be described by a model with (11) as the rds but they were in good agreement with a model based on (12), i. e. the rate of carbon formation, $r_{c}$ is well described by

$\mathrm{r}_{\mathrm{c}}=\mathrm{k} \frac{\mathrm{P}_{\mathrm{CO}}^{2}}{\left[1+\mathrm{K}_{\mathrm{A}} \mathrm{P}_{\mathrm{CO}}\right]^{2}}$

where $\mathrm{K}_{\mathrm{A}}$ is the equilibrium constant for $\mathrm{CO}$ adsorption. $\mathrm{K}_{\mathrm{A}}$ values giving best agreement between model and experimental results were in good agreement with values determined from surface science experiments [16]. A closer look at the results of Tфttrup [14] showed that only his results for carbon formation in $\mathrm{CO}+\mathrm{CO}_{2}$ gas mixtures were well described by a model based on (11) as rds. His results obtained in pure $\mathrm{CO}$ were in better agreement with (13).

\subsection{Kinetics of carbon formation on $\mathrm{Ni} / \mathrm{SiO}_{2}$ catalysts from $\mathrm{CO}+\mathrm{H}_{2}$ gas mixtures}

Tavares et al. [17] also studied the kinetics of carbon formation on the $\mathrm{Ni} / \mathrm{SiO}_{2}$ catalyst from $\mathrm{CO}+\mathrm{H}_{2}$ gas mixtures. In this case, a high rate of methanation was always measured independent of carbon formation. The carbon formation rate results showed that hydrogen has a far stronger influence than can be explained by simple blocking of sites on the surface. A good description was obtained by assuming, in agreement with results of coadsorption experiments [17], that adsorbed hydrogen diminishes the chemisorption bond energy of $\mathrm{CO}$. The modification giving good agreement consisted of introducing a simple linear dependence on hydrogen coverage.

\section{Equilibrium studies}

Already in the early studies of carbon formation from CO and $\mathrm{CH}_{4}$ by Dent et al. [18], attempts were made to characterize the thermodynamic properties of the carbon formed and it was observed that the equilibrium constants of reactions (3) und (4) were smaller than the equilibrium constants corresponding to the formation of graphite. Rostrup-Nielsen made a similar observation [19]. In addition he observed that the deviations depend on the nickel particle size and suggested that they could be explained by the extra energy required by the surface and defect structure of the carbon filaments.

It is important to realize that it is usually difficult to start carbon formation close to equilibrium conditions. A carbon activity, $\mathrm{a}_{\mathrm{C}}$, larger than the one corresponding to equilibrium is usually needed. In the work of Tavares et al. [16] and of Rostrup-Nielsen [19], it was observed that a significantly higher carbon activity was needed to start carbon formation on a fresh catalyst than on a used one. The determination of the carbon activity corresponding to equilibrium was made by decreasing the carbon activity of the gas in small steps until carbon formation could not be observed and then decreasing it a little further until gasification of the carbon was measurable. The equilibrium activity was then determined by interpolation. Estimates of the surface energy and elastic energy of the carbon filaments indicate that they can explain the main part of the deviations from graphite equilibrium, at least in the case of carbon formation from $\mathrm{CH}_{4}+$ $\mathrm{H}_{2}$ [20]. Tavares et al. [16] found that the deviation was larger when carbon was formed in $\mathrm{CO}+\mathrm{CO}_{2}$ than in $\mathrm{CH}_{4}+\mathrm{H}_{2}$.

\section{The influence of copper}

\subsection{Kinetics}

Similar kinetic studies were also performed for carbon formation on $\mathrm{Ni}_{1-\mathrm{x}} \mathrm{Cu}_{\mathrm{x}} / \mathrm{SiO}_{2}$ catalysts. The method used for catalysts preparation ("dry" impregnation) resulted for $\mathrm{x}<0.5$ in one alloy phase with a bulk composition equal to the nominal one, while two alloy phases were observed for $\mathrm{x} \geq 0.5$ [21]. Kinetic results were obtained for carbon formation on $\mathrm{Ni}_{0.99} \mathrm{Cu}_{0.01} / \mathrm{SiO}_{2}$ and $\mathrm{Ni}_{0.9} \mathrm{Cu}_{0.1} / \mathrm{SiO}_{2}$ catalysts exposed to $\mathrm{CH}_{4}+\mathrm{H}_{2}$ [22] at the same conditions as the above mentioned results for the $\mathrm{Ni} / \mathrm{SiO}_{2}$ catalyst. The kinetic model based on steps (6)-(10) with calculated equilibrium constants and with the $\mathrm{CH}_{4}$ chemisorption step (7) as rds gave, as mentioned above, a reasonable agreement with the experimental results for the $\mathrm{Ni} / \mathrm{SiO}_{2}$ catalyst. The agreement was further improved if also step (8) was treated as deviating from equilibrium. The models with only one rds have the advantage that they can be linearized, i.e. written as

$\mathrm{y}=\mathrm{ax}+\mathrm{b}$

With step (7) as rds we obtain

$\mathrm{x}=\frac{\mathrm{P}_{\mathrm{CH}_{4}}}{\mathrm{P}_{\mathrm{H}_{2}}^{2}}$ and $\mathrm{y}=\frac{\mathrm{r}_{\mathrm{C}}}{\mathrm{P}_{\mathrm{H}_{2}}^{2}}$

Using $\mathrm{a}$ and $\mathrm{b}$ as fitting parameters gave excellent fits to the results obtained for the $\mathrm{Ni} / \mathrm{SiO}_{2}$ catalyst [22]. Comparisons of plots of $y$ versus $x$ for the $\mathrm{Ni} / \mathrm{SiO}_{2}$ and the two alloy catalysts show that the kinetic model describes also the results for the $\mathrm{Ni}_{0.99} \mathrm{Cu}_{0.01} / \mathrm{SiO}_{2}$ catalyst very well and that the presence of 1 at $\% \mathrm{Cu}$ enhances the carbon formation rate. The results for the $\mathrm{Ni}_{0.9} \mathrm{Cu}_{0.01} / \mathrm{SiO}_{2}$ catalyst can, on the other hand, only be described by the same kinetic model at low values of $\mathrm{x}, \mathrm{i}$. e. at low carbon activities, $\mathrm{a}_{\mathrm{C}}$, and then the rate is much smaller than the rate for the $\mathrm{Ni} / \mathrm{SiO}_{2}$ catalyst. At higher values of $\mathrm{x}$ or $\mathrm{a}_{\mathrm{C}}$, the rate increases drastically and approaches the values obtained for the $\mathrm{Ni} / \mathrm{SiO}_{2}$ catalyst.

Also carbon formation in $\mathrm{CO}$ [16] and in $\mathrm{CO}+\mathrm{H}_{2}$ [17] is promoted by the presence of 1 at $\% \mathrm{Cu}$ to the $\mathrm{Ni}$ catalyst. The promotion increases strongly at higher hydrogen pressures [17]. $\mathrm{Cu}$ concentrations of 10 at\% or higher poison the carbon formation strongly. In both cases the same type of kinetic model describes the results well for $\mathrm{Cu}$ concentrations in the range $0-10$ at $\%$.

\subsection{Equilibrium}

The studies of the equilibrium of carbon formation in $\mathrm{CH}_{4}$ $+\mathrm{H}_{2}$ showed that it does not depend significantly on the $\mathrm{Cu}$ content of the catalyst for $\mathrm{Cu}$ concentrations in the range $0-50$ 
at $\%$ [21]. Equilibrium results in $\mathrm{CO}+\mathrm{CO}_{2}$ gas mixtures were independent of $\mathrm{Cu}$ concentrations in a smaller range, $0-10$ at $\%$, while higher deviations from graphite equilibrium were found at higher $\mathrm{Cu}$ contents [16]. The deviations from graphite equilibrium were significantly higher in $\mathrm{CO}$ $+\mathrm{CO}_{2}$ than in $\mathrm{CH}_{4}+\mathrm{H}_{2}$.

\section{Electron microscopic observations}

Systematic electron microscopic studies of catalysts after carbon formation at a range of different conditions have unfortunately not been made. However, a few chance observations are worthwhile mentioning.

\subsection{Surface planes of the active nickel particles}

Because of the structure sensitivity of the chemisorption of $\mathrm{CH}_{4}$ on nickel surfaces, it is important to know the structure of the various parts of the surface of the nickel particles responsible for the carbon formation. It turned out that it was possible to obtain this information by constructing a model of the particle in agreement with the particle contours in electron micrographs and the angles between the surface planes as determined from thickness fringes seen in weak beam, dark field images of the nickel particles [23]. The modelling showed that the surface of the nickel particle in the end of the filament consists of (111), (100), and (113) atomic planes making up 46,23 , and $31 \%$ of the total surface area, respectively. Unfortunately, no studies have been made of the interaction of $\mathrm{CH}_{4}$ with the $\mathrm{Ni}(113)$ surface. It may be expected that the sticking coefficient is higher for the (113) than for the (111) surface, perhaps even higher than for the (100) surface.

\subsection{Relation between the carbon filament structure and the nickel structure}

HREM lattice imaging of the interface between the carbon filament and the nickel particle shows that in spite of frequent interface direction changes due to low angle facetting, the graphite planes of the filament close to the interface are always strictly parallel to the interface.

\subsection{Ni particle shape as function of temperature}

Comparison of the nickel particles at the end of filaments grown in $\mathrm{CH}_{4}+\mathrm{H}_{2}$ gas at 763 and $863 \mathrm{~K}$ shows that the nickel particles with increasing temperature become more and more pear-shaped. The rear side of the particle develops into a cone pointing towards the filament, the lengths of the cone increasing with temperature. It may be suggested that the filament graphite planes in contact with the nickel particle during growth are acting on the nickel with a friction force drawing the metal out in a cone. At the higher temperature, the metal particle may be deformed to a higher extent. It is conceivable that if the temperature is high enough and the cohesive energy of the metal is low enough, then metal drops may be separated from the metal particle. We have observed such metal drops inside long, hollow carbon filament tubes after exposing a Cu/ $\mathrm{SiO}_{2}$ catalyst to a $\mathrm{CH}_{4}+\mathrm{H}_{2}$ gas mixture at about $1100 \mathrm{~K}$ [21].

\subsection{Carbon morphology}

Most of our EM observations of the carbon formed have been made after growth in $\mathrm{CH}_{4}+\mathrm{H}_{2}$ mixtures. In this case, we have always seen carbon filaments with more ordered and more disordered carbon after growth at high and low temperatures, respectively. Only one filament is connected with a pure nickel particle and the filament and particle have approximately the same size. Carbon filaments for $\mathrm{Ni}_{1-\mathrm{x}} \mathrm{Cu}_{\mathrm{x}}$ alloy catalysts with small $\mathrm{x}$ are not different from the filaments of the pure $\mathrm{Ni}$ catalysts. Another type of filaments is seen for $x \geq 1.0$. More than one filament ("octopus" carbon) have grown out of each almost spherical alloy particle [24]. In this case the graphite plans are perpendicular to the axis of the filament and the interfaces between the filaments and metal particle are plane facets. For higher values of $\mathrm{x}$, the carbon in the octopus carbon becomes more disordered [21].

EM micrographs obtained after carbon growth in $\mathrm{CO}$ show yet another type of carbon, i. e. encapsulating carbon. In this case the metal particles are completely covered by a number of graphite-like layers forming a shell around the particle.

\section{Discussion}

\subsection{Carbon formation on nickel from $\mathrm{CH}_{4}+\mathrm{H}_{2}$}

Very recently Snoeck et al. have published thorough discussions of the mechanism [25] and the kinetics [26] of carbon filament growth in $\mathrm{CH}_{4}+\mathrm{H}_{2}$ gas mixtures on a commercial nickel catalyst. The kinetic studies were made at 773,798 , and $823 \mathrm{~K}$ with $1.5,5.0$, and 10 bar $\mathrm{CH}_{4}$ partial pressures.

Snoeck et al. [25] advocate a model for carbon filament growth closely resembling the one suggested by Alstrup [20] in 1988. They agree that the "equilibrium" for carbon filament formation is determined by the thermodynamic properties of the carbon filaments and not, as suggested by some other authors $[27,28]$, by an intermediate, unstable carbide, although Snoeck et al. prefer not to call the gas composition where growth stops and gasification starts, or vice versa, for the "equilibrium" but the "coking threshold". The surface reaction, e.g. methane decomposition or the Boudouard reaction produces, at not too high rates, adsorbed, isolated carbon atoms, which dissolve into the nickel particle, diffuse through the particle and precipitate out at the support interface. Due to the segregation behaviour of carbon in nickel, a high concentration of carbon is established in the selvedge at the surface where the carbon atoms are produced. This high concentration, which is linked to surface carbon coverage and to the bulk concentration just below the selvedge, gives the driving force for the diffusion of carbon through the particle. In the induction period, a supersaturation is established in the particle, and faceting and nucleation of graphite precipitation take place at the particle/support interface and the carbon concentration at the interface drops to the solubility limit.

Snoeck et al. [26] made a careful analysis of all the possible kinetic models for carbon formation from $\mathrm{CH}_{4}$ decomposition based on one rate controlling step and the same sequence of surface steps as assumed in our model with one exception: They found it necessary to add molecularly adsorbed $\mathrm{CH}_{4}$ because the rate is significantly suppressed when the $\mathrm{CH}_{4}$ pressure is increased from 5 to 10 bar. The main problems in the modelling are the quantitative description of the steps transporting the carbon from the surface through the bulk and 
into the filament. In our model we got rid of them by assuming that surface carbon coverage can be treated as a constant. This is of course not strictly true but the good agreement obtained indicates that it may be a reasonable approximation. Snoeck et al. [26] have solved this problem more elegantly by assuming that the diffusion is so rapid that it is reasonable to assume that the concentration gradient is negligible in the particle so that the bulk concentration to a good approximation is equal to the solubility throughout the particle. The carbon coverage is assumed to be linked to the bulk concentration close to the surface by a segregation equilibrium constant. The end result is that Snoeck et al. [26] obtained a rate equation with the same partial pressure dependencies in the numerator as we did [4] when we assumed one rate controlling step. The denominator of their rate expression has an extra term accounting for the blocking action of the molecularly adsorbed $\mathrm{CH}_{4}$. They assume that molecularly adsorbed $\mathrm{CH}_{4}$ is the precursor for the dissociation of $\mathrm{CH}_{4}$. This is not necessarily the case, as the direct dissociative chemisorption observed by molecular beam experiments may still be dominating.

\subsection{Encapsulating carbon}

When carbon formation takes place in $\mathrm{CH}_{4}+\mathrm{H}_{2}$ or $\mathrm{CO}+$ $\mathrm{H}_{2}$ gas mixtures the most common type formed is filamentous carbon. However, when the carbon formation takes place in pure $\mathrm{CO}$, another type, encapsulating carbon, is dominating as mentioned above. Nolan et al. [29-31] have studied the influence of hydrogen on the morphology of carbon grown in $\mathrm{CO}$. They concluded that the presence of hydrogen is necessary for the growth of filaments. The role of hydrogen is to satisfy the free valencies of the open end of the filament.

\subsection{Challenges}

The studies reviewed above show that very detailed information about the surface steps of the carbon formation mechanism is obtainable from independent experiments and calculations. In the near future it may even be possible to follow the steps in situ at the atomic level using high pressure, elevated temperature STM technique. The next challenges will then be to perform similar detailed studies of the subsurface events, i. e. determining the structure and concentration in the subsurface layers, the nucleation of and incorporation of carbon atoms into filaments, and the formation of encapsulating carbon.

\section{Conclusions}

The kinetics of carbon filament formation in $\mathrm{CH}_{4}+\mathrm{H}_{2}$ on nickel catalysts is well described by a model consisting of

1. Dissociation of $\mathrm{CH}_{4}$, either directly from gas phase or from adsorbed $\mathrm{CH}_{4}$ molecules. The dissociation is the rate determining step.

2. Stepwise dehydrogenation.

3. Segregation-dissolution equilibrium linking carbon surface coverage and the bulk carbon concentration close to front surface.

4. Diffusion through particle.

5. Precipitation into the filament at the rear interface.

The carbon filaments become tubes with more perfect carbon structure at higher growth temperatures.
The deformation of the nickel particle with cone formation increases with temperature.

Carbon formation in pure $\mathrm{CO}$ results mainly in encapsulating carbon. The rate determining step is CO disproportionation.

Carbon formation in $\mathrm{CO}+\mathrm{H}_{2}$ gives filaments. The rate determining step is $\mathrm{CO}$ disproportionation. Adsorbed hydrogen has a strong poisoning effect on $\mathrm{CO}$ chemisorption.

$\mathrm{Cu}$ alloying:

Small amounts of $\mathrm{Cu}(\mathrm{Cu}: \mathrm{Ni}=1: 99)$ promotes carbon formation.

Larger amount of $\mathrm{Cu}(\mathrm{Cu}: \mathrm{Ni} \geq 10: 90)$ poisons carbon formation. The poisoning becomes smaller at higher $\mathrm{C}$ activities because of $\mathrm{Ni}$ surface segregation.

\section{Acknowledgment}

Part of this work has been supported by the Danish Research Councils through the Center for Surface Reactivity.

\section{References}

[1] R. T. K. Baker, M. A. Barber, P. S. Harris, F. S. Feates, R. J. Waite: J. Catal. 26 (1972) 51.

[2] L. S. Lobo, D. L. Trimm, J. L. Figueiredo: in: "Proceedings, 5th International Congress on Catalysis, Florida, 1972" (J. W. Hightower, Ed.), p. 1125, North-Holland, Amsterdam, 1973.

[3] R. T. K. Baker, P. S. Harris, R. B. Thomas, R. J. Waite: J. Catal. 30 (1973) 86.

[4] I. Alstrup, M. T. Tavares: J. Catal. 135 (1992) 147.

[5] M. B. Lee, Q. Y. Yang, S. L. Tang, S. T. Ceyer: J. Chem. Phys. 87 (1987) 2724

[6] P. M. Holmblad, J. Wambach, I. Chorkendorff: J. Chem. Phys. 102 (1995) 8255

[7] T. P. Beebe, Jr., D. W. Goodman, B. D. Kay, J. T. Yates, Jr.: J. Chem. Phys. 87 (1987) 2305.

[8] I. Chorkendorff, I. Alstrup, S. Ullmann: Surf. Sci. 227 (1990) 291.

[9] L. Hanley, Z. Xu, J. T. Yates, Jr.: Surf. Sci. Lett. 248 (1991) L265.

[10] B. Ø. Nielsen, A. C. Luntz, P. M. Holmblad, I. Chorkendorff: Cat. Let. 32 (1995) 15.

[11] F. C. Schouten, O. L. J. Gijzeman, G. A. Bootsma: Surf. Sci. 87 (1979) 1.

[12] L. C. Isett, J. M. Blakely: Surf. Sci. 58 (1976) 397.

[13] H. J. Grabke: Metall. Trans. 1 (1970) 2972.

[14] P. B. Tфttrup: J. Catal. 42 (1976) 29.

[15] N. Sakai, T. Chida, T. Tadaki, J. Shimoiizaka: J. Chem. Eng. Japan 18 (1985) 199.

[16] M. T. Tavares, I. Alstrup, C. A. Bernardo, J. R. Rostrup-Nielsen: J. Catal. 147 (1994) 525.

[17] M. T. Tavares, I. Alstrup, C. A. Bernardo, J. R. Rostrup-Nielsen: J. Catal. 158 (1996) 402.

[18] F. J. Dent, L. A. Moignard, A. H. Eastwood, W. H. Blackburn, D. Hebden: Trans. Inst. Gas. Eng. (1945-1946) 602.

[19] J. R. Rostrup-Nielsen: J. Catal. 27 (1972) 343.

[20] I. Alstrup: J. Catal. 109 (1988) 241.

[21] C. A. Bernardo, I. Alstrup, J. R. Rostrup-Nielsen: J. Catal. 96 (1985) 517.

[22] I. Alstrup, M. T. Tavares: J. Catal. 139 (1993) 513.

[23] O. Sørensen, M. T. Tavares, I. Alstrup: Proc. 20th Biennial American Carbon Conf., California 1991, p. 464.

[24] M. T. Tavares, C. A. Bernardo, I. Alstrup, J. R. Rostrup-Nielsen: J. Catal. 100 (1986) 545.

[25] J.-W. Snoeck, G. F. Froment, M. Fowles: J. Catal. 169 (1997) 240. 
[26] J.-W. Snoeck, G. F. Froment, M. Fowles: J. Catal. 169 (1997) 250.

[27] M. P. Manning, J. E. Garmirian, R. C. Reid: Ind. Eng. Chem. Process Des. Dev. 21 (1982) 404.

[28] A. J. H. M. Kock, P. K. de Bokx, E. Boellaard, W. Klop, J. W. Geus: J. Catal. 96 (1985) 468.

[29] P. E. Nolan, D. C. Lynch, A. H. Cutler: Carbon 34 (1996) 817.

[30] P. E. Nolan, M. J. Schabel, D. C. Lynch, A. H. Cutler: Carbon 33 (1995) 79.

[31] P. E. Nolan, D. C. Lynch, A. H. Cutler: Carbon 32 (1994) 477.

(Received: January 12, 1998)

W 3269 